\title{
Adenylyl Cyclase Responsiveness to Guanyl Nucleotides in the Developing Rat Heart
}

\author{
JULIA B. CLARK, ${ }^{(30)}$ FRANK VINICOR, LUCINDA CARR, AND CHARLES M. CLARK, JR.
}

Departments of Pharmacology and Medicine, Indiana University School of Medicine, and the Veterans Administration

Hospital, Indianapolis, Indiana, USA

\section{Summary}

Guanyl nucleotides are effective activators of rat heart adenylyl cyclase activity from the earliest age studied, 16 fetal days, through adulthood. Both guanosine triphosphate and guanylyl-imidodiphosphate (GMP-PNP) significantly enhance epinephrine-stimuIated adenylyl cyclase activity at all fetal and postnatal ages. The dose-response curves for epinephrine alone, GMP-PNP alone, or for the combination of epinephrine and GMP-PNP are similar for the newborn and adult heart preparations.

Our results indicate that the epinephrine-guanyl nucleotideadenylyl cyclase system is "mature" as a functional unit in the rat heart even prior to birth. The rat heart adenylyl cyclase system shows a dramatic increase in responsiveness to epinephrine and to guanyl nucleotides just before birth, a responsiveness which rapidly falls by 3 days of neonatal life. With increasing age, the absolute guanosine triphosphate or GMP-PNP activated rate rises in parallel with the basal rate of adenylyl cyclase activity in the rat heart.

\section{Speculation}

The activation of adenylyl cyclase systems by guanyl nucleotides may be a general feature of fetal as well as of adult tissues. This activation by guanyl nucleotides may magnify tissue hormonal responses at some stages of development.

Hormonal regulation of cardiac function develops early in fetal life in the rat and mouse. By the 16th day of a 22-day gestation, epinephrine increases the rate and strength of myocardial contraction and augments adenylyl cyclase activity $(5,23)$. The myocardial response to glucagon is, in contrast, species dependent. Glucagon increases the heart rate of the fetal mouse heart but does not activate adenylyl cyclase in either the fetal or adult mouse or guinea pig heart $(6,11,24)$. Glucagon increases both heart rate and adenylyl cyclase activity in the rat and sheep, but only after birth $(1,25)$.

Recently, we have demonstrated that the effect of glucagon on adenylyl cyclase can be augmented in early neonatal life by GTP or its analog, guanylyl-imidodiphosphate (GMP-PNP) (25). Because GTP is thought to be an important modulator of hormonal activation of adenylyl cyclase in a variety of tissues including the heart $(13,14)$, we examined further the development of myocardial adenylyl cyclase responsiveness to guanyl nucleotides and/or epinephrine during the fetal and early neonatal period. Studies on the effects of GTP and GMP-PNP on glucagon-activated adenylyl cyclase were performed for comparison. The results indicate that guanyl nucleotides augment adenylyl cyclase activity from at least the 16th day of gestation. In addition, guanyl nucleotides are synergistic with epinephrine at that date, suggesting maturation of the epinephrine-responsive adenylyl cyclase system in the fetal rat myocardium at a very early age. As previously reported, no effect of guanyl nucleotides on the glucagon-responsive adenylyl cyclase was demonstrated until at least 7 days after birth in the rat (25).

\section{MATERIALS AND METHODS}

Timed pregnant rats of the Sprague-Dawley strain were purchased to provide offspring of known gestational age (26). The maternal rats were later used to provide the adult animals. Newborn heart cells were isolated by the method previously described (7).

A washed heart particulate preparation was used in this study (8). Eight to ten newborn ( 3 days old) or 4 adult hearts are minced and washed with $0.25 \mathrm{M}$ sucrose--0.01 $\mathrm{M}$ Tris- $\mathrm{HCl}$, pH 7.4. This and all further procedures are carried out at $4^{\circ} \mathrm{C}$. The pieces are then homogenized in $25 \mathrm{ml}$ of the Tris-sucrose buffer for $15 \mathrm{sec}$ with a Polytron PT-20 (setting 4.5). The homogenate is filtered through two layers of cheese cloth, diluted to $50 \mathrm{ml}$ with Trissucrose buffer, and centrifuged at $1600 \times g$. The resulting pellet is resuspended in a small volume of Tris-sucrose buffer and used immediately. This particulate preparation was modified slightly for fetal hearts to increase the yield. The specific activity is not changed by the modification. About forty 16-day or twenty-four 18- or 21-day fetal hearts are homogenized and diluted in $12.5 \mathrm{ml}$ of the Tris-sucrose buffer. The Polytron homogenization is shortened to $5 \mathrm{sec}$, and the filtration is eliminated. A number of preparations $(N)$ were tested for each age group to provide the data shown in Figures 2 and 3. For the studies using $10^{-4} \mathrm{GMP}$ PNP (Fig. 2), $N=6$ for the 16 fetal day value; $N=10$ for 18 fetal days; $N=10$ for 21 fetal days; $N=4$ for 3 days; $N=4$ for 1 week; $N=4$ for 2 weeks; $N=5$ for 3 weeks; $N=9$ for 4 weeks; $N=4$ for adult. For the studies using $10^{-4} \mathrm{M}$ GTP (Fig. 3), $N=6$ for the 16 fetal day value; $N=10$ for 18 fetal days; $N=10$ for 21 fetal days; $N=3$ for 3 days; $N=4$ for 1 week; $N=4$ for 2 weeks; $N=4$ for 3 weeks; $N=2$ for 4 weeks, $N=16$ for adult.

The standard conditions of the assay for adenylyl cyclase activity were determined in preliminary experiments to yield linear rates for the formation of cyclic adenosine, $3^{\prime}: 5^{\prime}$-monophosphate (AMP) with time and protein concentration as variables. In the present study, standard assay conditions for adenylyl cyclase activity consist of 40 to $200 \mu \mathrm{g}$ of protein preincubated for $7 \mathrm{~min}$ at $37^{\circ} \mathrm{C}$ in a final volume of $0.06 \mathrm{ml}$ containing $3.3 \mathrm{mM} \mathrm{MgCl}$, $5.5 \mathrm{mM} \mathrm{KCl}, 8 \mathrm{mM}$ theophylline, $0.1 \%$ bovine serum albumin, 20 $\mathrm{mM}$ phosphoenol pyruvate, $13 \mu \mathrm{g}$ pyruvate kinase, and $50 \mathrm{mM}$ Tris-HCl, $\mathrm{pH}$ 7.6. The reaction is started with the addition of $[\alpha-$ ${ }^{32}$ P]ATP (1 to $2 \times 10^{6} \mathrm{cpm}$; final concentration, $1.0 \mathrm{mM}$ ). The preincubation eliminates a "lag time" when the reaction containing GTP or GMP-PNP alone is started by the addition of membrane. The reaction is terminated $10 \mathrm{~min}$ later by placing the tubes on ice and immediately adding $3 \mathrm{mM}$ ATP and $1 \mathrm{mM}\left[{ }^{3} \mathrm{H}\right]$ cAMP $(40,000 \mathrm{cpm})$. The tubes are then boiled $3.5 \mathrm{~min}$, and 0.9 $\mathrm{ml}$ water is added to each tube. The $\left[{ }^{32} \mathrm{P}\right] \mathrm{cAMP}$ is separated from $\left[\alpha-{ }^{32}\right.$ P]ATP on Dowex AG-X4 (200 to 400 mesh) columns and ${ }^{3} \mathrm{H}$ 
and ${ }^{32} \mathrm{P}$ are measured by liquid scintillation counting (18). The pmoles of cAMP formed are calculated from the recovery of $\left[{ }^{3} \mathrm{H}\right]$ cAMP, subtraction of "blanks" $\left({ }^{32} \mathrm{P}\right.$ counts recovered in the absence of membranes), and the specific activity of $\left[\alpha^{32}\right.$ P]ATP. The blank values account for $10 \%$ or less of the reaction values. The Biuret method is used to determine protein concentration (9). Points in the Figures 1 to 3 are shown \pm S.E. unless the S.E. is too small to be shown. Comparisons of basal rates with stimulated rates were made with Student's $t$ test. Points were considered significantly different for $P<0.05$ or less.

We found that newborn myocardial adenylyl cyclase activity is readily stimulated by GMP-PNP in contrast to our previous observations (25). To resolve these conflicting data, we investigated two differences in our experimental techniques: (1) the use of an homogenized tissue versus a whole-cell preparation; and (2) the change in the assay conditions. We found that the adenylyl cyclase activity of newborn whole myocardial cells is insensitive to GMP-PNP using the previous assay conditions but shows a four-fold stimulation by GMP-PNP using the present assay conditions $(2.4 \pm 0.1 \mathrm{pmol} / \mathrm{min} / \mathrm{mg}$ protein, basal activity; $9.0 \pm 0.02$ $\mathrm{pmol} / \mathrm{min} / \mathrm{mg}$ protein, activity with $10^{-4} \mathrm{M}$ GMP-PNP). Furthermore, the washed particulate preparation of newborn myocardial adenylyl cyclase activity is stimulated by GMP-PNP using either assay condition. We conclude that our earlier failure to demonstrate activation of adenylyl cyclase activity by GMP-PNP in newborn heart cells was a methodologic problem.

ATP, AMP, GMP-PNP, GTP, l-epinephrine, glucagon, bovine serum albumin, phosphoenol pyruvate, and pyruvate kinase, type 2 or type 3, were obtained from Sigma Chemical Co (28). [ $\left.\alpha-{ }^{32} \mathrm{P}\right]$ ATP, 10 to $16 \mathrm{Ci} / \mathrm{mmole}$, and $\left[{ }^{3} \mathrm{H}\right] \mathrm{cAMP}, 30$ to $50 \mathrm{Ci} / \mathrm{mmole}$, were purchased from New England Nuclear (27). All other chemicals were analytical grade.

\section{RESULTS}

The adenylyl cyclase activity of the newborn heart particulate fraction responds to $l$-epinephrine or GMP-PNP in a dose-dependent manner similar to that of the adult (Fig. 1). GMP-PNP, $10^{-4}$ $\mathrm{M}$, augments the adenylyl cyclase response to concentrations of $l$ -

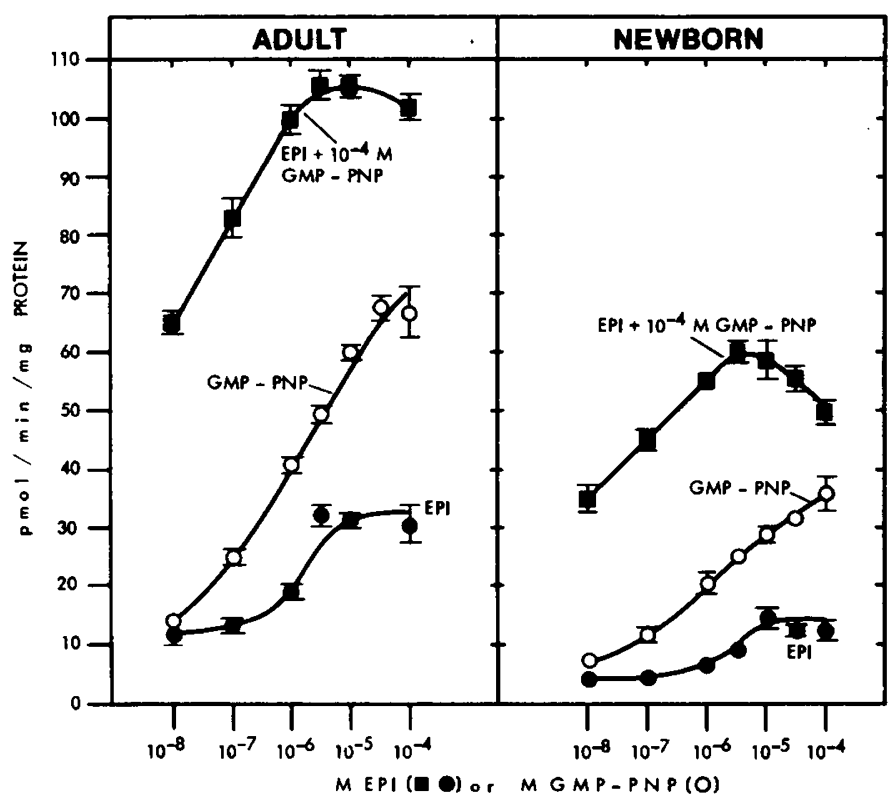

Fig. 1. Dose-response curves to epinephrine and GMP-PNP. Epinephrine concentrations were varied in the absence $(\theta)$ and presence $(\square)$ of $10^{-4}$ M GMP-PNP. GMP-PNP concentrations were varied in the absence (O) of epinephrine. The graph for each age is representative of 3 experiments. epinephrine of $10^{-7} \mathrm{M}$ and higher. GMP-PNP also shifts the response curve of adenylyl cyclase toward lower concentrations of $l$-epinephrine at both ages.

The ontogenesis of responsiveness to guanylyl nucleotides, $l$ epinephrine and glucagon is depicted in Figures 2 and 3. Either $10^{-4}$ M GMP-PNP or GTP stimulates adenylyl cyclase activity of the heart particulate fraction over basal at all ages studied. Epinephrine, $10^{-5} \mathrm{M}$, also stimulates the adenylyl cyclase activity of the heart even in the fetal period. Although the stimulation by epinephrine is not statistically significant at 16 days of gestation, significant responsiveness to this hormone is noted at 18 fetal days and older. Furthermore, $10^{-5} \mathrm{M}$ epinephrine acts synergistically with either GMP-PNP or GTP at fetal ages and at least additively after birth.

Of particular interest is the peak in guanyl nucleotide sensitive adenylyl cyclase activity just prior to birth (Figs. 2 and 3). A more modest peak in activity is noted with $l$-epinephrine alone. In contrast, the basal adenylyl cyclase activity shows a gradual doubling from 16 fetal days to adulthood.

In contrast to epinephrine, $10^{-5} \mathrm{M}$ glucagon did not significantly augment adenylyl cyclase activity in the rat heart until 4 weeks after birth in the absence of GMP-PNP or GTP. In the presence of $10^{-4} \mathrm{M}$ GMP-PNP or GTP, glucagon synergistically increased adenylyl cyclase activity after birth. This effect was statistically significant in this study in myocardial particles from 3-week-old rats.

\section{DISCUSSION}

This study indicates that guanyl nucleotides are effective activators of rat heart adenylyl cyclase activity from the earliest age studied, 16 fetal days, through adulthood. Furthermore, both GTP and GMP-PNP significantly enhance the epinephrine-stimulated adenylyl cyclase activity at all fetal and postnatal ages. The doseresponse curves for epinephrine, GMP-PNP, or for the combination of epinephrine and GMP-PNP are remarkably similar in newborn and adult hearts, although the specific activity in the newborn heart is significantly lower than in the adult heart in both basal and stimulated states. Several studies have shown that the adenylyl cyclase activity of fetal rat or human heart $(5,12,15$, $16,22)$ and of newborn rat $(5,12)$ is stimulated by epinephrine or norepinephrine. Our results indicate that the epinephrine-guanyl nucleotide-adenylyl cyclase system is "mature" as a functional unit in the rat heart even prior to birth.

The rat heart adenylyl cyclase system shows a dramatic increase in responsiveness to epinephrine and to guanyl nucleotides just before birth, a responsiveness which rapidly falls by 3 days of neonatal life. During this period, the basal activity shows a modest (less than two-fold) rise which does not fall after birth. With increasing age, the absolute GTP or GMP-PNP activated rate rises in parallel with the basal rate of adenylyl cyclase in the rat heart. These observations are in agreement with Thompson et al. (21), who reported that the responsiveness of adenylyl cyclase to GMP-PNP and isoproterenol was cyclical during development (21). Our studies do not reveal which factors might account for the increased responsiveness to guanyl-nucleotides and epinephrine of the late fetal rat heart adenylyl cyclase activity. Because the basal activity does not peak in the late fetal period, this responsiveness is unlikely to reflect the extent of washing of endogenous nucleotide pools from the particulate preparation. The $\beta$-receptor and guanyl nucleotide binding protein are regarded as two separate protein units distinct from the adenylyl cyclase catalytic protein. A change in the ratio of these three components in the fetal heart membrane could therefore account for the increase in response before birth. It is clear that some kinetic parameter, a $V_{m}$ value for the stimulated system at least, differs in the fetal and adult adenylyl cyclase systems because the assay conditions favor maximal activity for the newborn and adult systems. 


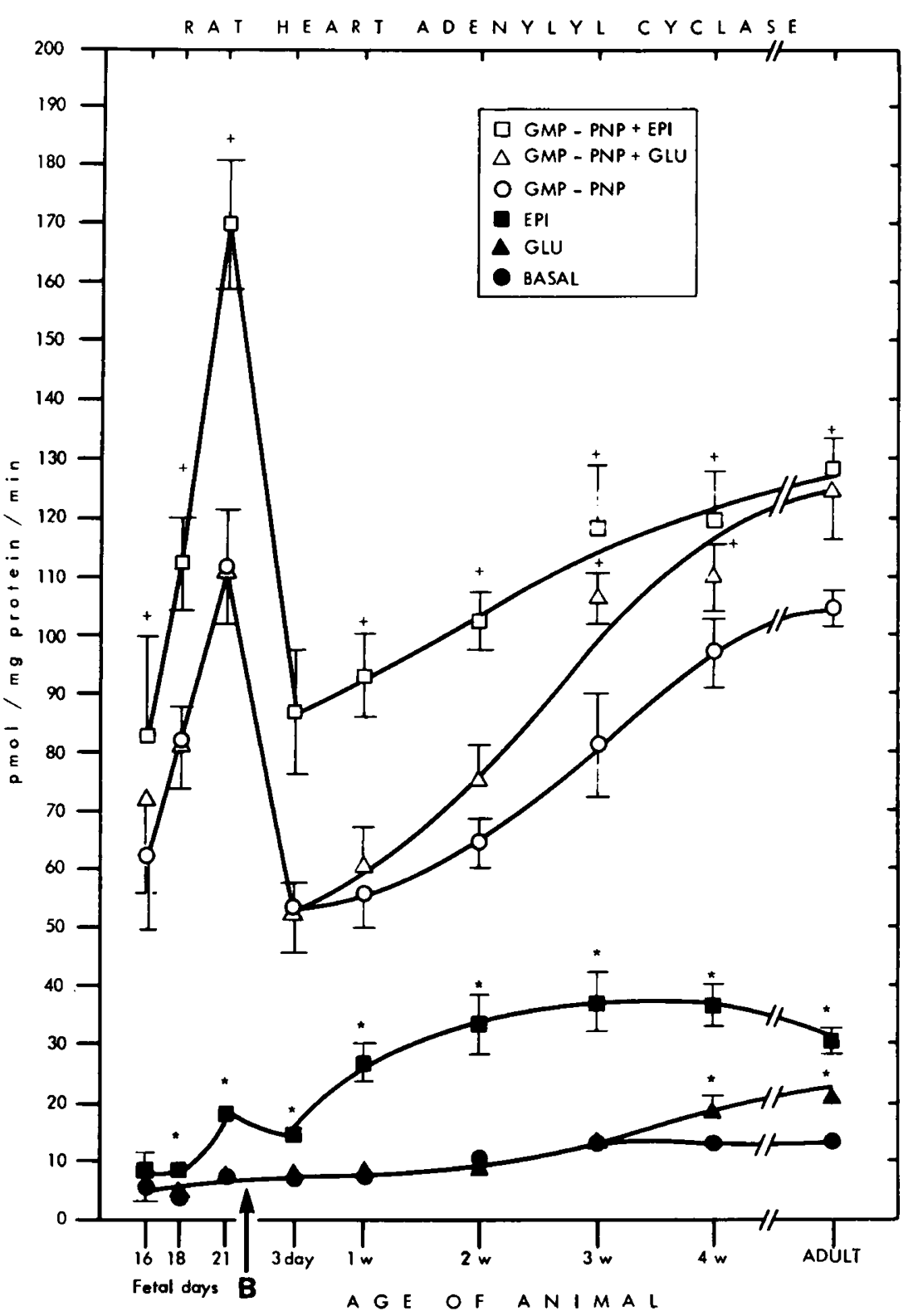

Fig. 2. Development of adenylyl cyclase activities. Assays were performed as described in the text: $\bigcirc$, no hormone; $\Delta, 10^{-5} \mathbf{M}$ glucagon; $\square, 10^{-5} \mathrm{M}$ epinephrine; $O, 10^{-4} \mathrm{M}$ GMP-PNP; $\triangle, 10^{-4} \mathrm{M}$ GMP-PNP $+10^{-5} \mathrm{M}$ glucagon; $\square 10^{-4} \mathrm{M}$ GMP-PNP $+10^{-5} \mathrm{M}$ epinephrine. ${ }^{*}$, rate with hormone alone was greater than basal; + , rate with hormone $10^{-4} \mathrm{M}$ GMP-PNP was significantly greater than the rate with $10^{-4} \mathrm{M}$ GMP-PNP alone. The rate with $10^{-4} \mathrm{M}$ GMP-PNP alone was significantly greater than basal at all ages.

Although GTP alone stimulates adenylyl cyclase activity of the rat heart less than two-fold, GMP-PNP activates adenylyl cyclase 8-12 fold. This difference in effectiveness between GTP and GMP-PNP has also been described for turkey erythrocytes (14). In that system, the lower effectiveness of GTP has been attributed to the hydrolysis of the adenylyl cyclase-bound GTP to GDP, a reaction which results in the dissociation of GDP and a concomitant loss of activated adenylyl cyclase. This hydrolysis step is negligible with GMP-PNP $(14,17)$. Our data also show that the effect of $10^{-4} \mathrm{M} \mathrm{GMP-PNP}$ is to lower by ten-fold the concentration of epinephrine needed for half-maximal stimulation of adenylyl cyclase. This effect of GMP-PNP has also been described for the $\beta$-receptor of turkey erythrocytes $(13,19)$.

In contrast to epinephrine, glucagon is ineffective in stimulating either basal or guanyl nucleotide-stimulated adenylyl cyclase activity of the fetal and newborn rat heart. There is an age-dependent development of glucagon-stimulated adenylyl cyclase activity in the rat heart which can be most clearly seen in the presence of
$10^{-4}$ M GMP-PNP. In the presence of GMP-PNP, glucagon and epinephrine are almost equally effective in stimulating adenylyl cyclase activity of the adult rat heart. However, epinephrine alone is more effective in stimulating adenylyl cyclase activity than is glucagon alone in heart preparations from all ages.

These current results confirm our earlier work which demonstrated an age-dependent development of glucagon-stimulated adenylyl cyclase activity in the rat heart (25). We have also shown that epinephrine, but not glucagon, increases heart rate and depletes myocardial glycogen when administered to the intact newborn rat (22). We further found that newly cultured newborn rat heart cells respond to epinephrine with an increased heart rate and increased cAMP concentrations but do not so respond to glucagon until after 4 weeks of culture (4). Maturation of tissue function has been associated with changes in the hormonal responsiveness of adenylyl cyclase in several other tissues, including the response to glucagon and epinephrine by the liver and lung, and to catecholamines by the submaxillary gland $(2,3,10,20,23)$. 


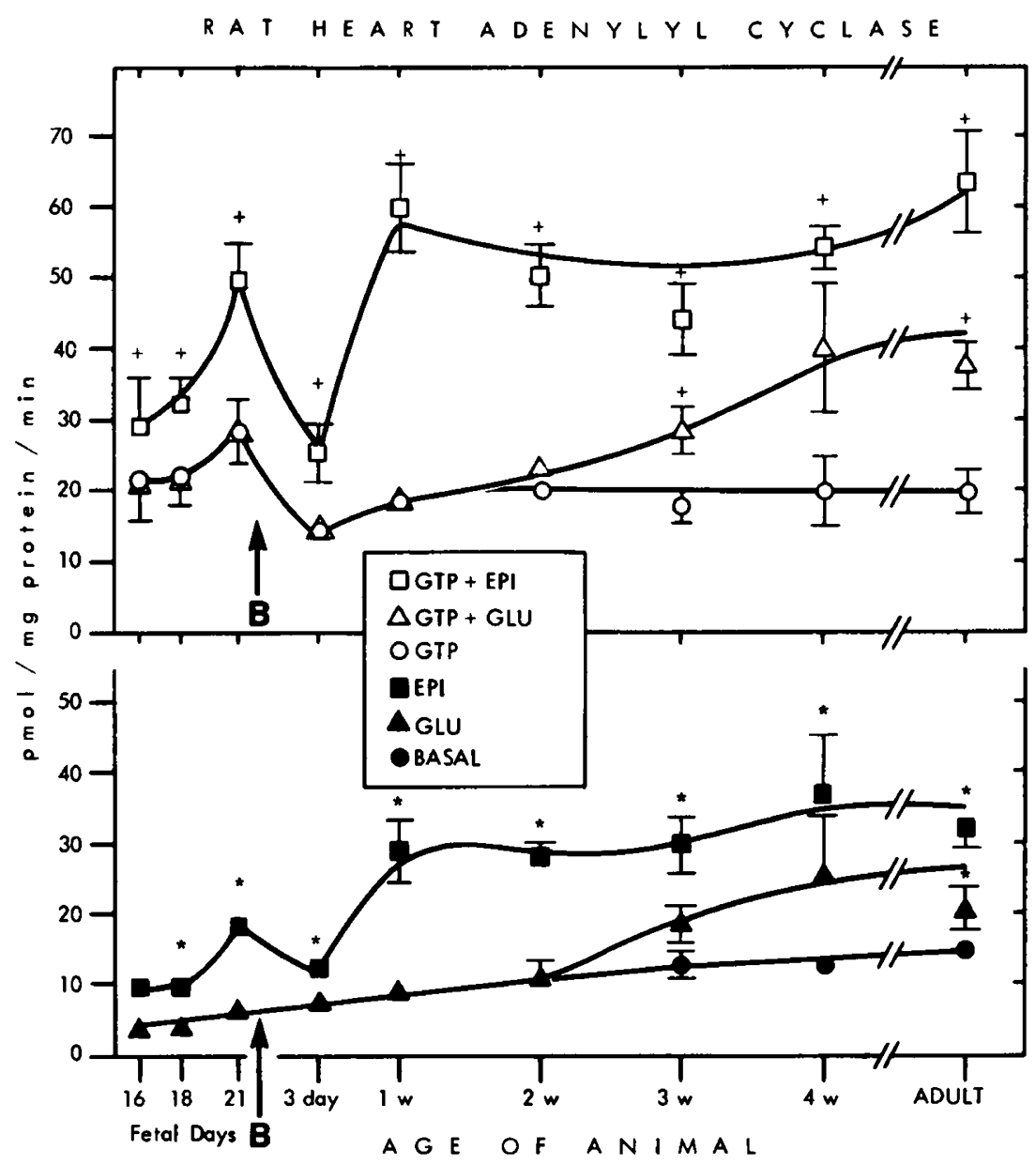

Fig. 3. Development of adenylyl cyclase activities. Assays were performed as described in the text: $O$, no hormone; $\Delta, 10^{-5} M$ glucagon; $\square, 10^{-5} M$ epinephrine; $O, 10^{-4} \mathrm{M} \mathrm{GTP} ; \Delta, 10^{-4} \mathrm{M} \mathrm{GTP}+10^{-5} \mathrm{M}$ glucagon; $\square, 10^{-4} \mathrm{M}$ GTP $+10^{-5} \mathrm{M}$ epinephrine. *, rate with hormone was significantly greater than basal. + , rate with hormone $+10^{-4} \mathrm{M}$ GTP was significantly greater than with $10^{-4} \mathrm{M}$ GTP alone. The rate with $10^{-4} \mathrm{M}$ GTP alone was significantly greater than basal at all ages.

We now show that guanyl nucleotides regulate epinephrine responsiveness in fetal rat heart. The mechanism(s) of this effect of guanyl nucleotides remains to be established.

\section{CONCLUSION}

The adenylyl cyclase system of fetal and newborn rat heart is stimulated by epinephrine and guanyl nucleotides, alone or in combination. Guanyl nucleotides increase the responsiveness of the heart adenylyl cyclase activity to epinephrine at all ages studied.

\section{REFERENCES AND NOTES}

1. Ahumada, G., Sobel, B. E., and Friedman, W. F.: Age-dependent mechanical and biochemical responses to glucagon. Am. J. Physiol., 230: 1590 (1976).

2. Barrett, C. T., Sevanian, A., and Kaplan, S. A.: Adenylate cyclase activity in immature rabbit lung. Pediatr. Res., 8: 244 (1974).

3. Christoffersen, T., and Oye, I.: Alterations in hormone responsiveness of hepatic adenylate cyclase during ontogenesis and oncogenesis. Acta Endocrinol. Suppl., 77: 67 (1971).

4. Clark, C. M., Jr., Allen, D. O., and Clark, J. F.: Appearance of responses to glucagon in cultured neonatal rat heart cells. Endocrinology, 100: 989 (1977).

5. Clark, C. M., Jr., Beatty, B., and Allen, D. O.: Evidence for the delayed development of the glucagon receptor of adenylate cyclase in the fetal and neonatal rat heart. J. Clin. Invest., 52: 1018 (1973).

6. Clark, C. M., Jr., Waller, D., Kohalmi, D., Gardner, R., Clark, J., Levey, G., Wildenthal, K., and Allen, D.: Evidence that cyclic AMP is not involved in the chronotropic action of glucagon in the adult mouse heart. Endocrinology, 98: 23 (1976).

7. Clark, J. B., and Clark, C. M., Jr.: Kinetics of insulin-stimulated accumulation of glucose by heart cells from newborn rats. Biol. Neonate, 30: 150 (1976).
8. Fricke, R.: The effect of guanine nucleotides on glucagon-sensitive adenylate cyclase in the rat heart. (Ph.D. thesis, Indiana University, 1975).

9. Gornall, A. G., Bardarvill, C. J., and David, M. M.: Determinations of serum proteins by means of Biuret reaction. J. Biol. Chem., 177: 751 (1949).

10. Grand, R. J., Chong, D. A., and Ryan, M. C.: Postnatal development of adenylate cyclase in rat salivary glands: patterns of hormonal sensitivity. Am. J. Physiol. 228: 608 (1975).

11. Henry, P. D., Dobson, J. G., Jr., and Sobel, B. E.: Dissociations between changes in myocardial adenosine monophosphate and contractility. Circ. Res., 36: 392 (1975).

12. Kohrman, A. F.: Patterns of development of adenyl cyclase activity and norepinephrine responsiveness in the rat. Pediatr. Res., 7: 575 (1973).

13. Lefkowitz, R. J., Mullihis, D., and Caron, M. C.: Regulation of $\beta$-adrenergic receptors by guanyl-5'-yl imidodiphosphate and other purine nucleotides. $J$. Biol. Chem., 251: 4686 (1976).

14. Levitzki, A.: The role of GTP in the activation of adenylate cyclase. Biochem. Biophys. Res. Commun., 74: 1154 (1977).

15. Martin, S., Levey, B. A., and Levey, G. S.: Development of the cardiac beta adrenergic receptor in fetal rat heart. Biochem. Biophys. Res. Commun., 54: 949 (1973).

16. Palmer, G. C., and Dail, W. G., Jr.: Appearance of hormone-sensitive adenylate cyclase in the developing human heart. Pediatr. Res., 9: 98 (1975).

17. Rodger, N., Jacobs, S., and Cuatrecasas, P.: Activation of adenylate cyclase by guanosine S'- $\alpha, \beta$-methylene triphosphate. Life Sci., 21: 1193 (1977).

18. Salomon, Y., Londos, C., and Rodbell, M.: A highly sensitive adenylate cyclase assay. Anal. Biochem., 58: 541 (1974).

19. Sevilla, N., Steer, M. L., and Levitzki, A.: Synergistic activation of adenylate cyclase by guanylyl imidodiphosphate and epinephrine. Biochemistry, 15:3493 (1976).

20. Sicard, R. E., and Aprille, J. R.: Developmental changes in rat liver adenylate cyclase. J. Cell Biol., 70: 238a (1976).

21. Thompson, W. J., Strada, S. J., Couture-Murillo, B., and Robison, G. A Differential development of rat heart adenylyl cyclase and receptor binding. Pharmacologist, 19: 202 (1977).

22. Vinicor, F., Clark, J. F., and Clark, C. M., Jr.: Development of hormone receptors in the isolated fetal rat heart. In: R. A. Camerini-Davalos, H. S. Cole: Early 
Diabetes in Early Life. p. 105 (Academic Press, Inc., New York, 1975).

23. Vinicor, F., Higdon, G., Clark, J., and Clark, C. M., Jr.: Development of glucagon sensitivity in neonatal rat liver. J. Clin. Invest., $58: 571$ (1976).

24. Wildenthal, K., Allen, D. O., Karlsson, J., Wakeland, J. R., and Clark, C. M., Jr.: Responsiveness to glucagon in fetal hearts. J. Clin. Invest., 57: 551 (1976)

25. Yount, A., Clark, J. F., and Clark, M., Jr.: Development of guanylyl-imidodiphosphate (GMP-PNP)-Dependent activation of adenylate cyclase by glucagon in the neonatal rat heart. Pediatr. Res., 10: 851 (1976).

26. Charles River Breeding Laboratories, Wilmington, MA.

27. New England Nuclear, Boston, MA.
28. Sigma Chemical Company, St. Louis, MO.

29. Special acknowledgements are made to Susan Wills and Lynne Holzhausen for their technical assistance and to Peggy Schwartz and Julie Metcalf for their preparation of the manuscript.

30. Requests for reprints should be addressed to: Dr. Julia B. Clark, Department of Pharmacology, 1100 West Michigan Street, Indianapolis, IN 46223 (USA).

31. This research was supported by a grant from the American Heart Association and Veterans Administration Research Funds.

32. Received for publication January 10, 1979.

33. Accepted for publication July 12, 1979.

Copyright $\odot 1980$ International Pediatric Research Foundation, Inc.

Printed in U.S.A. 0031-3998/80/1404-0291\$02.00/0 